$\begin{array}{llcccccr}\text { Volume } & 12, \quad \text { Nomor } & 1, \quad \text { Mei } & 2020, & \text { pp } & 123-136 & \text { Copyright } & \text { C2017 } \\ \text { Jurnal } & \text { Akuntansi, } & \text { Program } & \text { Studi } & \text { Akuntansi, } & \text { Fakultas } & \text { Ekonomi, } \\ \text { Universitas } & \text { Kristen } & \text { Maranatha } & \text { ISSN } & 2085-8698 & \text { e-ISSN } & 2598-4977 .\end{array}$

http://journal.maranatha.edu

\title{
Pengaruh Corporate Social Responsibility terhadap Kinerja Perusahaan dengan Good Corporate Governance sebagai Variabel Moderasi pada Perusahaan Manufaktur di Bursa Efek Indonesia Periode 2015-2017
}

\author{
Tiopan Naek \\ Fakultas Ekonomi Program Studi Akuntansi Universitas Kristen Maranatha \\ (Jl. Prof. drg. Suria Sumantri No. 65, Bandung) \\ tiopan.naeksinurat@gmail.com \\ Lauw Tjun Tjun \\ Fakultas Ekonomi Program Studi Akuntansi Universitas Kristen Maranatha \\ (Jl. Prof. drg. Suria Sumantri No. 65, Bandung) \\ lauwtjuntjun@gmail.com
}

\begin{abstract}
This study aims to analyze the effect of Corporate Social Responsibility on Firm Performance with Good Corporate Governance as a moderating variable. This study uses a simple random sampling method. Samples were taken from 40 manufacturing companies listed on the Indonesia Stock Exchange in the 2015-2017 period. Test the hypothesis using multiple linear regression analysis. It was found that the effect of Good Corporate Governance that moderates Corporate Social Responsibility on Firm Performance is $18.8 \%$.
\end{abstract}

Keywords: Corporate Social Responsibility, Good Corporate Governance, and Firm Performance

\begin{abstract}
Abstrak
Penelitian ini bertujuan untuk menganalisis pengaruh corporate social responsibility terhadap kinerja perusahaan dengan good corporate governance sebagai variabel moderasi. Penelitian ini memakai metode pengambilan sampel secara probabilitas random sederhana (simple random sampling). Sampel diambil dari 40 perusahaan manufaktur yang listing di Bursa Efek Indonesia pada periode 2015 - 2017. Uji hipotesis menggunakan analisis regresi linier berganda. Didapat bahwa pengaruh good corporate governance yang memoderasi corporate social responsibility terhadap kinerja perusahaan adalah sebesar $18.8 \%$.
\end{abstract}

Kata Kunci: Corporate Social Responsibility, Good Corporate Governance, dan Kinerja Perusahaan 


\section{Pendahuluan}

Corporate Social Responsibility muncul sebagai pendekatan dan kerangka kerja penting untuk menyikapi peran bisnis dalam masyarakat, menetapkan standar perilaku yang harus dikerjakan oleh perusahaan untuk mempengaruhi masyarakat secara positif dan efektif sekaligus mematuhi nilai-nilai yang mengecualikan pencarian keuntungan. dengan biaya berapa pun. Bukti empiris menjelaskan tindakan Corporate Social Responsibility mengarah pada kemajuan kinerja perusahaan (Dabas, 2011).

CSR merupakan sebuah kewajiban perusahaan dalam menyelesaikan masalah lingkungan yang disebabkan oleh aktivitas perusahaan. Saat ini CSR bukan sebuah kebijakan yang sukarela untuk perusahaan dalam mengembangkan tanggungjawabnya melaksanakan kegiatan usahanya, tetapi sudah diwajibkan bagi corporate.Dalam menjalankan tanggungjawab sosial yang paling diutamakan adalah memperkuat keberlanjutan perusahaan dan membuat kerjasama para pemegang saham dalam menjalankan program peningkatan masyarakat di daerah tersebut (Kholida \& Susilo, 2019).

Tanggung Jawab Sosial Perusahaan (CSR) merupakan konsep global dan saat ini sangat populer di dunia bisnis.CSR semakin berkembang menjadi topik hangat ketika pelanggaran etika bisnis perusahaan yang kian berkembang. Entitas dalam menjalankan bisnisnya, tidak peduli masyarakat dan lingkungan sekitarnya, sehingga membuat hubungan timbal balik antara komunitas dan perusahaan. Perusahaan membutuhkan respons positif dari masyarakat memperoleh melalui apa yang dilakukan perusahaan terhadapnya pemangku kepentingan, termasuk masyarakat dan lingkungan sekitarnya (Kamil, et., al., 2012). Tanggung jawab ini disampaikan kepada pemangku kepentingan melalui pengungkapan tanggung jawab sosial perusahaan (CSR). Pengungkapan
CSR baik secara dimensi ekonomi, lingkungan sosial, hak asasi manusia, komunitas, atau produk tanggung jawab berdasarkan Inisiatif Pelaporan Global (GRI) digunakan sebagai sinyal dari manajemen untuk semua pemangku kepentingan termasuk investor tentang prospek perusahaan di masa depan, bahwa perusahaan memiliki sinyal positif atas kebutuhan sehari-hari perusahaan di masa depan. Implementasi CSR di perusahaan dapat memiliki hubungan jangka panjang yang baik dengan pemangku kepentingan (Castelo \& Lima, 2006).

Dampak tanggung jawab sosial perusahaan terhadap kinerja perusahaan telah menjadi topik perdebatan para peneliti.Berbagai penelitian dilakukan untuk mengeksplorasi dampak tanggung jawab sosial perusahaan atas kinerja perusahaan.Teknik dan Metode yang digunakan oleh berbagai peneliti berbeda, dan pendapat berbeda tentang hasilnya. Beberapa peneliti menemukan dampak positif CSR pada kinerja perusahaan, sedangkan peneliti lainnya menunjukkan dampak negatif/netral, diantara para peneliti tersebut, yaitu:

- Yang \& Chang (2010), menemukan bahwa dampak negatif dari tanggung jawab sosial perusahaan terhadap kinerja perusahaan.

- Simionescu \& Gherghina (2014), menemukan hubungan negatif antara CSR dan ROS, serta hubungan positif antara CSR dan EPS. Selanjutnya, dengan memperkirakan model regresi data panel efek tetap, hubungan positif antara CSR dan EPS diperkuat.

- Khanifar, Nazari, Emami, \& Soltani (2012), menemukan dampak yang positif dan negatif antara tanggung jawab sosial perusahaan dan kinerja keuangan hotel, restoran dan perusahaan penerbangan. Temuan menunjukkan hasil yang beragam di berbagai industri dan akan berkontribusi pada pengambilan keputusan strategis perusahaan yang tepat untuk kegiatan 
CSR dengan memberikan informasi yang lebih tepat mengenai dampak dari masing-masing kegiatan CSR terarah.

Karena kesenjangan itulah maka penelitian ini menjadikan CSR dan kinerja perusahaan sebagai variabel dalam penelitian ini.Perbedaan penelitian ini dengan penelitian sebelumnya:

1. Pengambilan sampel perusahaan di Bursa Efek Indonesia,

2. Penelitian ini menggunakan variabel GCG sebagai variabel moderasi,

3. Pengukuran pengungkapan CSR menggunakan Global Reporting Initiative (GRI 4) dengan dummy.

Berdasarkan paparan diatas, maka rumusan masalahnya:

1) Apakah Corporate Social Responsibility berpengaruh terhadap kinerja perusahaan?

2) Apakah Good Corporate Governance berpengaruh terhadap kinerja perusahaan?

3) Apakah Good Corporate Governance memoderasi Corporate Social Responsibility terhadap Kinerja Perusahaan

Sehingga diharapkan praktik CSR dan pengungkapannya dan pengaruhnya terhadap kinerja perusahaan serta GCG menjadi hal yang umum dan dibutuhkan di masa depan.

\section{Kerangka Teoritis dan Hipotesis}

\section{Teori Stakeholder (Stakeholders Theory)}

Teori Stakeholder, berpendapat jika keberadaan corporate ditentukan pemegang saham. Perusahaan akan mencari kebenaran daripara stock holders dalam melaksanakan kegiatan perusahaannya. Semakin besar kekuasaan pemegang saham, maka semakin besar keinginan perusahaan mengadaptasi diri kepada kemauan para pemegang sahamnya (Sembiring, 2003).

\section{Teori Legitimasi}

Teori legitimasi menyebutkan jika perusahaan mempunyai kontrak dengan masyarakat (Fatoni, dkk, 2016). Di teori legitimasi di sebutkan bahwa perusahaan mengusahakan agar sesuai dengan peraturan yang ada dimasyarakat umum agar diterima dilingkungan luar karena di teori legitimasi menyebutkan jika perusahaan akan bertahan kalau masyarakat di sekitar merasa perusahaan berjalan dengan kemauan yang sama dengan kemauan masyarakat (Sari, 2013).

\section{Corporate Social Responsibility}

CSR merupakan sebuah system agar corporate dengan cuma-Cuma mau memberikan perhatiannya ke dalam masyarakat di dalam kegiatan usahanya dan berinteraksi bersama para stock holders (Darwin, 2004), bukan hanya profit semata sebagai tujuan utama korporasi (Friedman,2006).

\section{Kinerja Perusahaan}

Danu Candra (2011) menyatakan bahwa kinerja perusahaan hal yang dibuat corporate dijangka waktu tertentu dan bertujuan dalam kewajiban yang ditentukan.Seharusnya kinerja perusahaan sesuatu yang bisa diukur dan menjelaskan situasi empiris suatu perusahaan yang telah disetujui.Iman Widodo (2011) menjelaskan bahwa kinerja adalah ungkapan dari kondisi keseluruhan perusahaan dalam jangka waktu tertentu, merupakan sumber daya yang dimiliki berdasarkan hasil yang terpengaruhi oleh kegiatan operasional perusahaan.

\section{Good Corporate Governance}

Dalam usaha untuk menambah nilai perusahaan, GCG dapat dimaksudkan dalam struktur, sistem, dan proses yang dipakai organisasi di perusahaan (IICG, 2010).Fairness, Disclosure, Accountability, Responsibility, dan Independency adalah dasar-dasar dari prinsip GCG telah dibuatkan jadi indikator. 


\section{Pengembangan Hipotesis}

Pengaruh Corporate Social Responsibility (CSR) Terhadap Kinerja Perusahaan

Perusahaan menggunakan CSR, dalam kegiatan manajemen dengan harapan mendorong inovasi dan meningkatkan kinerja sosial perusahaan (Păunescu, 2014). CSR dan kinerja perusahaan membuktikan biaya eksplisit corporate bukan biaya tersembunyi untuk pemangku kepentingan. Dengan kata lain, jika kepuasan para pemangku kepentingan, mis. lingkungan, pelanggan, karyawan, dan sebagainya dipertimbangkan maka biaya yang digunakan oleh perusahaan untuk praktik corporate social responsibility akan jauh lebih rendah daripada manfaat corporate social responsibility (Yuan, Bao, \& Verbeke, 2011), hal tersebut akan meningkatkan kinerja perusahaan. H1: Corporate Social Responsibility berpengaruh positif terhadap kinerja perusahaan

Pengaruh Good Corporate Governance (GCG) Terhadap Kinerja Perusahaan

Pelaksanaan GCG diyakini bisa meningkatkan kinerja perusahaan.Gunawan \& Sutiono (2018) menyatakan GCG dengan komisaris, direksi dan ukuran perusahaan mempunyai pengaruh terhadap kinerja perusahaan.Veno, Andri (2015) menyatakan bahwa variabel GCG mempunyai pengaruh yang besar atas kinerja perusahaan.

H2: Good Corporate Governance berpengaruh positif terhadap kinerja perusahaan.

Good Corporate Governance memoderasi Corporate Social Responsibility terhadap Kinerja Perusahaan

GCG adalah cara yang digunakan dalam memberi kepercayaan bagi para investor perusahaan dan akan didapatkan return atas investasi mereka (La Porta, Silanes, Shleifer, and Vishny, 1997).Keadaan lain GCG yang di samakan berdasarkan level pengungkapan corporate social 126 responsibility di pelaporan tahunan perusahaan. Hasilnya menunjukkan adanya korelasi positif. Penganut paham CG suka mendapatkan keharusan dalam menjalankan CSR hal tersebut di sebabkan karena pemahaman falsafahnya sama.

$\begin{array}{lcr}\text { H3: Good } & \text { Corporate } & \text { Governance } \\ \text { memoderasi } & \text { corporate } & \text { social } \\ \text { responsibility } & \text { terhadap } & \text { kinerja } \\ \text { perusahaan } & & \end{array}$

\section{Rerangka Pemikiran}

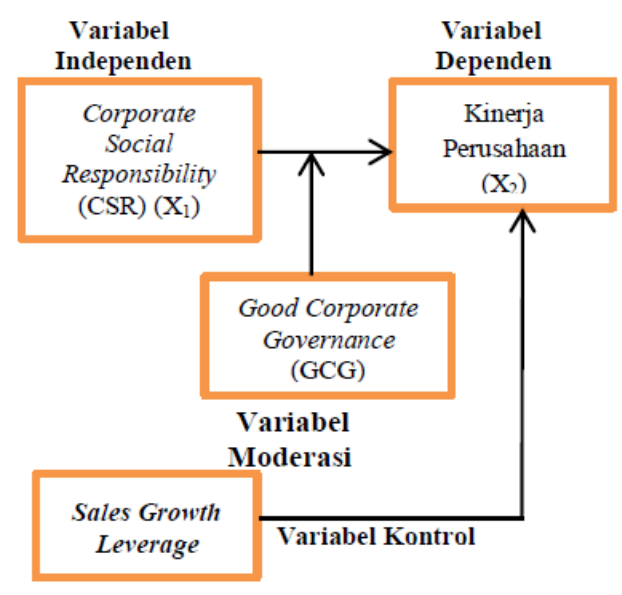

\section{Gambar 1 \\ Rerangka Pemikiran}

\section{Metode Penelitian}

\section{Jenis Penelitian}

Penelitian yang dilakukan bertujuan untuk menganalisis CSR sebagai variabel independen dengan kinerja perusahaan dan GCG sebagai variabel pemoderasi. Jenis penelitian ini yaitu explanatory kuantitatif.

\section{Populasi Penelitian}

Populasi merupakan subjek yang ingin diuji. Populasi dapat dikatakan sebagai universe. Populasi biasanya merupakan benda hidup ataupun benda mati, yang mana sifatnya bisa diukur maupun dapat diamati (Radjab \& Jam'an, 2017).Populasi didalam penelitian ini adalah 144 
perusahaan manufaktur yang terdaftar di BEI periode 2015-2017.

Kriteria populasi yang di pilih oleh peneliti adalah:

1. Semua perusahaan yang telah terdapat di Bursa Efek Indonesia dalam periode 2015-2017

2. Mengeluarkan financial report yang lengkap dalam jangka waktu 2015-2017.

3. Mempunyai laporan CSR dan GCG.

4. Memiliki data yang dibutuhkan untuk perhitungan variabel-variabel penelitian ini.

\section{Sampel Penelitian}

Pengambilan sampel digunakan dengan metode secara probabilitas random sederhana, yaitu pengambilan sampel yang member giliran sama kepada populasi agar dijadikan sampel (Enny, 2017). Sampelnya adalah 40 perusahaan manufaktur yang terdaftar di BEI periode 2015-2017.

\begin{tabular}{|c|c|c|}
\hline No & Kode & Nama \\
\hline 1. & ALMI & Alumindo Light Metal Industry Tbk \\
\hline 2. & BAJA & Saranacentral Bajatama Tbk \\
\hline 3. & BTON & Beton Jaya Manunggal Tbk \\
\hline 4. & CTBN & Citra Turbindo Tbk \\
\hline 5. & GDST & Gunawan Dianjaya Steel Tbk \\
\hline 6. & INAI & Indal Aluminium Industry Tbk \\
\hline 7. & INTP & Indocement Tunggal Prakasa Tbk \\
\hline 8. & SMBR & Semen Baturaja Persero Tbk \\
\hline 9. & SMCB & $\begin{array}{l}\text { Holcim Indonesia Tbk } d . h \text { Semen } \\
\text { Cibinong Tbk }\end{array}$ \\
\hline 10. & SMGR & $\begin{array}{l}\text { Semen Indonesia Tbk d.h Semen } \\
\text { Gresik Tbk }\end{array}$ \\
\hline 11. & WTON & Wijaya Karya Beton Tbk \\
\hline 12. & AMFG & Asahimas Flat Glass Tbk \\
\hline 13. & ISSP & Steel Pipe Industry of Indonesia TBK \\
\hline 14. & JKSW & Jakarta Kyoei Steel Work LTD Tbk \\
\hline 15. & JPRS & Jaya Pari Steel Tbk \\
\hline 16. & KRAS & Krakatau Steel Tbk \\
\hline
\end{tabular}

\begin{tabular}{|c|c|c|}
\hline 17. & LION & Lion Metal Works Tbk \\
\hline 18. & LMSH & Lionmesh Prima Tbk \\
\hline 19. & ARNA & Arwana Citra Mulia Tbk \\
\hline 20. & IKAI & Inti Keramik Alam Asri Industri Tbk \\
\hline 21. & KIAS & Keramika Indonesia Assosiasi Tbk \\
\hline 22. & MLIA & Mulia Industrindo Tbk \\
\hline 23. & TOTO & Surya Toto Indonesia Tbk \\
\hline 24. & ALKA & Alaska Industrindo Tbk \\
\hline 25. & NIKL & Pelat Timah Nusantara Tbk \\
\hline 26. & PICO & Pelangi Indah Canindo Tbk \\
\hline 27. & TBMS & Tembaga Mulia Semanan Tbk \\
\hline 28. & BRPT & Barito Pasific Tbk \\
\hline 29. & BUDI & $\begin{array}{l}\text { Budi Starch and Sweetener Tbk d.h } \\
\text { Budi Acid Jaya Tbk }\end{array}$ \\
\hline 30. & DPNS & Duta Pertiwi Nusantara \\
\hline 31. & IGAR & $\begin{array}{l}\text { Champion Pasific Indonesia Tbk } d . h \\
\text { Kageo Igar Jaya Tbk }\end{array}$ \\
\hline 32. & IMPC & Impack Pratama Industri Tbk \\
\hline 33. & IPOL & Indopoly Swakarsa Industry Tbk \\
\hline 34. & SIAP & Sekawan Intipratama Tbk \\
\hline 35. & SIMA & Siwani Makmur Tbk \\
\hline 36. & TALF & Tunas Alfin Tbk \\
\hline 37. & TRST & Trias Sentosa Tbk \\
\hline 38. & YPAS & Yana Prima Hasta Persada Tbk \\
\hline 39. & CPIN & Charoen Pokphand Indonesia Tbk \\
\hline 40. & JPFA & Japfa Comfeed Indonesia Tbk \\
\hline
\end{tabular}

\section{Variabel Penelitian}

1. Variabel Independen

Corporate Social Reponsibility Indeks (CSRI) merupakan indeks untuk pengukuran CSR.Dan perhitungan CSR menggunakan GRI 4 (Global Reporting Initiatives).Checklist GRI merupakan indikator yang di pakai dalam komponen pengungkapan, standar universal, standar ekonomi, standar lingkungan, dan standar sosial untuk sustainability reporting dengan pengukuran variabel dummy. Diberi nilai 1 jika diungkapkan dan di beri nilai 
0 jika tidak di ungkapkan (Arifulsyah \& Nurulita, 2016; Haniffa \&Cooke, 2005).

2. Variabel Dependen

a. Return on Equity (ROE)

Rasio menunjukkan berapa tinggi kontribusi dari equity untuk earning merupakan pengertian dari ROE (Hery, 2015). Rumus ROE :

$$
\begin{gathered}
R O E=\frac{\text { Earning After Tax }(E A T)}{\text { Shareholders 'Equity }} \\
\times 100 \%
\end{gathered}
$$

Keterangan :

Earning After Tax (EAT): Laba Setelah Pajak

Shareholders' Equity : Modal Sendiri atau Total Modal Pemegang Saham

b. Return on Sale (ROS)

Pengukuran kemampuan perusahaan dalam menciptakan laba dengan pembagian laba atas total penjualan merupakan rumusan dari ROS.Perusahaan dapat menghasilkan ROS yang tinggi jika mempunyai laba yang tinggi dan itu akan menunjukkan kemampuan perusahaan pada tingkat tertentu. Dengan tidak efisien kinerja keuangan perusahaan akan membuat ROS menjadi rendah. Berikut ini adalah rumus dalam menghitung ROS, yaitu:

$$
R O S=\frac{\text { Income Before Tax }}{\text { Sales }} \times 100 \%
$$

Keterangan :

Income Before Tax: Laba Sebelum Pajak

Sales: Penjualan

3. Variabel Pemoderasi

a. Kepemilikan Manajerial

Jumlah persentase saham dimiliki manajer ataupun direksi adalah pengukuran Kepemilikan Manajerial.

$$
M A N J=\frac{D D+D K}{\sum \text { Saham Beredar }} \times 100 \%
$$

Keterangan :

$\mathrm{DD}=$ saham dewan direksi

DK = saham dewan komisaris

$\Sigma$ Saham Beredar = jumlah saham yang beredar.

b. Kepemilikan Institusional

Pengukuran persentase saham di akhir tahun adalah Kepemilikan Institusional.

$$
\begin{aligned}
& \text { INST }=\frac{S I+S B}{\sum \text { Saham Beredar }} \times 100 \% \\
& \text { Keterangan : } \\
& \text { INST= institutional ownership } \\
& \text { SI = jumlah saham institusi } \\
& \text { SB = jumlah saham blockholder } \\
& \Sigma \text { Saham Beredar = jumlah saham } \\
& \text { yang beredar }
\end{aligned}
$$

4. Variabel Kontrol

a. Penjualan Perusahaan (Sales GGrowth)

Peningkatan penjualan dari dalam sebuah periode sampai periode berikutnya merupakan istilah dari Sales Growth (Sutantoputra, 2009). Pertumbuhan sales dirumuskan dengan :

Keterangan:

$$
\Delta s=\frac{S_{t}-S_{t-1}}{S_{t-1}}
$$

$\Delta \mathrm{s} \quad=$ Sales growth

$\mathrm{S}_{\mathrm{t}} \quad=$ Penjualan tahun sekarang

$\mathrm{S}_{\mathrm{t}-1}=$ Penjualan tahun sebelumnya

b. Leverage Perusahaan (LEV)

Pengukuran dengan digunakan dalam menghitung kewajiban hutang perusahaan adalah leverage. Rumus leverage adalah:

$$
\text { Leverage }=\frac{\text { Total Hutang }}{\text { Total Aset }}
$$

\section{Hasil Penelitian dan Pembahasan}

\section{Uji Asumsi Klasik \\ Uji Normalitas}

Uji yang di lakukan agar nilai residual di distribusikan secara normal atau tidak merupakan pengujian normalitas di model 
regresi.Analisis uji normal $P-P$ plot dan uji One Sample Kolmogorov-Smirnov merupakan pengujian yang digunakan.

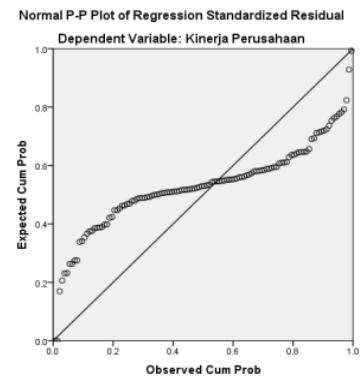

Berdasarkan uji Grafik di atas, didapat bahwa kecenderungan data sudah mendekati garis lurus, yang berarti bahwa kecenderungan dari data dapat dikatakan mengikuti kecenderungan distibusi normal. Namun, hal ini harus didukung dengan pengujian one sample kolmogorov smirnov:

Tabel 1

Hasil Uji Normalitas

One-Sample Kolmogorov-Smirnov Test

\begin{tabular}{|c|c|c|}
\hline & $\begin{array}{l}\text { Mahalanobis } \\
\text { Distance }\end{array}$ \\
\hline $\begin{array}{l}\mathrm{N} \\
\text { Normal } \\
\text { Parameters } \\
\text { Most Extreme } \\
\text { Differences } \\
\text { Kolmogorov-Sr } \\
\text { Asymp. Sig. (2 }\end{array}$ & $\begin{array}{l}\text { Mean } \\
\text { Std. Deviation } \\
\text { Absolute } \\
\text { Positive } \\
\text { Negative } \\
\text { lov Z } \\
\text { led) }\end{array}$ & $\begin{array}{r}120 \\
6.9416667 \\
14.39842608 \\
.322 \\
.319 \\
-.322 \\
1.530 \\
.062\end{array}$ \\
\hline
\end{tabular}

Didapatkan nilai signifikan sebesar 0.062, yang berarti melebihi nilai syarat yang ditentukan adalah 0.05.Maka dianggap perhitungan data sudah memenuhi kriteria, yang berarti data memiliki distribusi normal.

\section{Uji Multikolinearitas}

Supaya melihat jika terdapat korelasi di sekitar variabel bebas maka di lakukan uji multikolinearitas.Dan melihat Variance Inflation Factor (VIF) dan tolerance maka akan mengetahui ada atau tidaknya regresi di dalam multikolineritasnya. Apakah ada atau tidaknya multikolinearitas adalah dengan 10 melihat batas multikolinearitas mendekati 1 . Tidak adanya multikolinearitas adalah jika hasilnya ada nilai VIF dibawah nilai 10 dan mendekati 1 (Ghozali, 2005:92 dalam Suwati, 2013:46).

Tabel 2

Hasil uji Multikolinearitas

\begin{tabular}{|l|r|r|}
\hline \multirow{2}{*}{ Model } & \multicolumn{2}{|c|}{ Collinearity Statistics } \\
\cline { 2 - 3 } & \multicolumn{1}{|c|}{ Tolerance } & \multicolumn{1}{c|}{ VIF } \\
\hline (Constant) & .512 & 1.955 \\
CSR & .176 & 5.676 \\
CSR Kepemilikan & & \\
Manajerial & .234 & 4.282 \\
CSR ${ }^{\star}$ Kepemilikan & .179 & 5.595 \\
Institusional & .268 & 3.736 \\
MANJ & .929 & 1.077 \\
INST & .871 & 1.149 \\
Sales Growth & \\
Leverage &
\end{tabular}

Berdasarkan pengujian model regresi linier berganda, peneliti menemukan nilai VIF untuk variabel yang diteliti adalah sebagai berikut:

- $\quad$ Variabel CSR nilai VIF $=1.955$

- Variabel interaksi CSR*Kepemilikan Manajerial nilai $\mathrm{VIF}=5.676$

- Variabel CSR*Kepemilikan Institusional nilai VIF $=4.282$

- Variabel Kepemilikan Manajerial nilai $\mathrm{VIF}=5.595$

- Variabel Kepemilikan Institusional nilai VIF $=3.736$

- Variabel Sales Growth nilai VIF = 1.077

- $\quad$ Variabel Leverage nilai VIF $=1.149$

Berdasarkan hasil ini, didapat bahwa seluruh variabel yang diteliti sudah memiliki nilai VIF yang ada di bawah 10.Maka, didapat hasilnya tidak menunjukkan gejala multikolinearitas.

\section{Uji Heteroskedastisitas}

Menurut Yudiaatmaja (2013:82), uji heteroskedastisitas mempunyai tujuan mengetahui apakah ada perbedaan varian residual penelitian yang satu dengan 
penelitian yang sudah ada. Jika muncul tidak sama variannya, maka ada persoalan heteroskedastisitas. Jika terdapat heteroskedastisitas, jadi persamaan yang dihasilkan bukan persamaan yang bersifat BLUE (Best Linear Unbias Estimator).Analisis Uji Heteroskedastisitas dalam penelitian ini menggunakan uji Glejser, dimana nilai signifikansi hitung yang diteliti harus memiliki signifikansi > 0.05 .

Tabel 3

Uji Heteroskedastisitas

\begin{tabular}{|l|r|r|}
\hline Model & $\mathrm{t}$ & \multicolumn{1}{l|}{ Sig. } \\
& & \\
\hline (Constan) & .000 & 1.000 \\
CSR & .000 & 1.000 \\
CSR ${ }^{\star}$ Kepemilikan & .000 & 1.000 \\
Manajerial & & \\
CSR ${ }^{\star}$ Kepemilikan & .000 & 1.000 \\
Institusional & .000 & 1.000 \\
MANJ & .000 & 1.000 \\
INST & .000 & 1.000 \\
Sales Growth & .000 & 1.000 \\
Leverage & & \\
\hline
\end{tabular}

Berdasarkan tabel di atas, didapat untuk seluruh independen variabel memiliki nilai signifikansi sebesar 1.000. Dengan demikian, tidak terdapat pengaruh antara nilai independen variabel dengan nilai residual. Dengan demikian, tidak terdapat gejala heteroskedastisitas.

\section{Uji Autokorelasi}

Jika muncul korelasi antara sampel yang telah diurutkan, data satu terpengaruh dengan data lainnya. Autokorelasi ada di regresi yang memiliki data yang berkala. Kriteria Durbin-Watson:
a. DW $<-2=$ autokorelasi positif
b. DW -2 sampai $+2=$ tidak terdapat autokorelasi
c. $\quad$ DW $>+2=$ terdapat autokorelasi yang negatif

Tabel 4

Analisis Durbin Watson

\begin{tabular}{|l|c|c|r|}
\hline Model & $R$ & $\begin{array}{c}R \\
\text { Square }\end{array}$ & \multicolumn{2}{|c|}{ Durbin-Watson } \\
\hline 1 & $.434^{\mathrm{a}}$ & .188 & 1.599 \\
\hline
\end{tabular}
demikian, nilai ini ada di rentang -2 dan dengan +2 jadi tidak ada autokorelasi didata penelitian ini. Hasil dari penelitian ini juga diuji dengan uji Run Test, sebagai berikut:

Tabel 5

Analisis Uji Autokorelasi

\begin{tabular}{|l|l|}
\hline & $\begin{array}{l}\text { Unstandardized Resid } \\
\text { ual }\end{array}$ \\
\hline Test Value & 1773.71215 \\
Cases < Test Value & 60 \\
Cases >= Test Value & 60 \\
Total Cases & 120 \\
Number of Runs & 66 \\
Z & .917 \\
Asymp. Sig. (2-tailed) & .359 \\
\hline
\end{tabular}

a. Median

Berdasarkan analisis run test, didapat signifikansi $=0.359$. Peneliti menemukan hasil penelitian ini memiliki kecenderungan untuk tidak menunjukkan gejala Autokorelasi baik positif maupun negatif.

\section{Uji Hipotesis Untuk H1: CSR Berpengaruh Positif Terhadap Kinerja Perusahaan}

Model persamaan regresi yang di lakukan pengujian di hipotesis ini adalah:

$\mathrm{KP}=\alpha \_0+\llbracket \alpha \rrbracket \_1 \mathrm{CSR}+\alpha \_2 \mathrm{Sal}+$ $\alpha \_3 \operatorname{Lev}+\mathrm{e}$

Dengan taraf kepercayaan 95\%, maka hipotesis yang diuji adalah:

H01:CSR tidak berpengaruh positif terhadap kinerja perusahaan

Ha1:CSR berpengaruh positif terhadap kinerja perusahaan 
Hasil pengujian $\mathrm{H} 1$ ini adalah sebagai berikut:

\section{Tabel 6}

Hasil Pengujian H1 ANOVA ${ }^{\mathrm{a}}$

\begin{tabular}{|c|c|c|c|c|c|}
\hline Model & $\begin{array}{l}\text { Sum of } \\
\text { Squares }\end{array}$ & df & $\begin{array}{c}\text { Mean } \\
\text { Square }\end{array}$ & F & Sig. \\
\hline $\begin{array}{l}\text { Regres } \\
\text { sion } \\
\text { Residu } \\
\text { al } \\
\text { Total }\end{array}$ & $\begin{array}{l}11570811532 . \\
861 \\
50713593349 . \\
485 \\
62284404882 . \\
345\end{array}$ & 119 & $\begin{array}{l}3856937177 \\
620 \\
437186149 . \\
565\end{array}$ & 8.822 & $.000^{\mathrm{b}}$ \\
\hline
\end{tabular}

a. Dependent Variable: Kinerja Perusahaan

b. Predictors: Konstanta, Leverage, Sales Growth, CSR

Untuk Hipotesis 1 dihasilkan nilai signifikansi hitung 0.000 , menunjukkan signifikansi dibawah dari 0,05.Jadi, tolak H01 dan terima Ha1, yang artinya CSR berpengaruh positif terhadap kinerja perusahaan.

\section{Tabel 7}

Analisis Uji Hipotesis Untuk H1 Model Summary ${ }^{\mathrm{b}}$

\begin{tabular}{|l|l|l|l|l|}
\hline Model & R & $\begin{array}{l}\text { R } \\
\text { Squar } \\
e^{2}\end{array}$ & $\begin{array}{l}\text { Adjusted } \\
\text { Square }\end{array}$ & $\begin{array}{l}\text { Std. Error of the } \\
\text { Estimate }\end{array}$ \\
\hline 1 & $431^{\mathrm{a}}$ & 186 & 165 & 20908.99686 \\
\hline
\end{tabular}

a. Predictors: Konstanta, Leverage, Sales Growth, CSR

b. Dependent Variable: Kinerja Perusahaan

Dalam tabel 7 dihasilkan $R$ square sebesar 0.186. Maka:

Koefisien Determinan $=\mathrm{R}^{2} \times 100 \%$

Koefisien Determinan $=0.186 \times 100 \%$

Koefisien Determinan $=18.6 \%$

Dengan demikian, CSR memiliki pengaruh terhadap kinerja perusahaan sebesar $18.6 \%$.

Penerapan GCG diyakini dapat membuat peningkatan kinerja dari suatu perusahaan. Menurut Dey Report (1994) dan, Kusumawati, Dwi Novi dan Bambang Riyanto (2005) menyatakan GCG sebaiknya penerapannya di jangka waktu lama akan memberikan keuntungan kepada investor dan membuat peningkatan kinerja perusahaan.
Uji Hipotesis Untuk H2: GCG Berpengaruh Positif Terhadap Kinerja Perusahaan

Model persamaan regresi yang di lakukan pengujian di hipotesis ini adalah:

$\mathrm{KP}=\alpha \_0+\llbracket \alpha \rrbracket 1 \mathrm{CSR}+\alpha 2 \mathrm{MANJ}+$ $\alpha \_3 \mathrm{INST}+\alpha \_4 \mathrm{SAL}+\alpha \_5 \mathrm{LEV}+\mathrm{e}$

Dengan taraf kepercayaan 95\%, maka hipotesis yang diuji adalah sebagai berikut:

H02: GCG tidak berpengaruh positif

terhadap kinerja perusahaan

Ha2: GCG berpengaruh positif terhadap

kinerja perusahaan

Hasil pengujian $\mathrm{H} 02$ ini dapat dilihat dalam tabel 3, dibawah ini:

Tabel 8

Hasil Pengujian $\mathrm{H}_{2}$

ANOVA $^{\mathrm{a}}$

\begin{tabular}{|c|c|c|c|c|c|}
\hline Model & Sum of Squares & df & $\begin{array}{l}\text { Mean } \\
\text { Square }\end{array}$ & $F$ & Sig. \\
\hline Regression & 11672538287.837 & 5 & $\begin{array}{l}23345076 \\
57.567\end{array}$ & $\begin{array}{l}5.2 \\
58\end{array}$ & $.000^{\mathrm{b}}$ \\
\hline Residual & 50611866594.508 & 114 & $\begin{array}{l}44396374 \\
2.057\end{array}$ & & \\
\hline Total & 62284404882.345 & 119 & & & \\
\hline
\end{tabular}

a. Dependent Variable: Kinerja Perusahaan

b. Predictors: Konstanta, Leverage, Sales Growth, MANJ, INST, CSR

Untuk Hipotesis 2 dihasilkan nilai signifikansi hitung 0.000 , yang menunjukkan dibawah dari 0,05.Jadi, tolak $\mathrm{H} 02$ dan terima $\mathrm{Ha}$, artinya GCG berpengaruh positif terhadap kinerja perusahaan.

Tabel 9

Analsis Uji Hipotesis Untuk H2

Model Summary ${ }^{\mathrm{b}}$

\begin{tabular}{|l|l|l|l|l|}
\hline Model & $\mathrm{R}$ & $\begin{array}{l}\mathrm{R} \\
\text { Square }\end{array}$ & $\begin{array}{l}\text { Adjusted } \\
\text { R Square }\end{array}$ & $\begin{array}{l}\text { Std. Error of the } \\
\text { Estimate }\end{array}$ \\
\hline 1 & $.433^{\mathrm{a}}$ & .187 & .152 & 21070.44713 \\
\hline
\end{tabular}

a. Predictors: Konstanta, Leverage, Sales Growth, MANJ, INST, CSR

b. Dependent Variable: Kinerja Perusahaan 
Dalam tabel 9 dihasilkan R square sebesar 0.188. Maka:

Koefisien Determinan $=\mathrm{R}^{2} \times 100 \%$

Koefisien Determinan $=0.187 \times 100 \%$

Koefisien Determinan $=18.7 \%$

Dengan demikian, pengaruh GCG terhadap kinerja perusahaan adalah sebesar $18.7 \%$.

GCG adalah cara yang digunakan dalam meyakinkan investor perusahaan akan di perolehnya return atas investasi yang telah dilakukan (Shleifer dan Vishny, 1997). Orang yang menggunakan GCG akan lebih tertarik dengan adanya kebutuhan untuk menggunakan CSR dikarenakan CSR dan GCG memiliki falsafah yang serupa. CSR berkaitan dengan kewajiban corporate dengan pihak-pihak yang mempunyai kepentingan dan CSR merupakan kegiatan yang dilakukan corporate dalam menaikkan kesejahteraan masyarakat umum di samping kegiatan corporate.

Uji Hipotesis Untuk H3: GCG Tidak Memoderasi CSR Terhadap Kinerja Perusahaan

Model persamaan regresi yang dilakukan pengujian di hipotesis ini adalah:

$\mathrm{KP}=\alpha \_0+\llbracket \alpha \rrbracket \_1 \mathrm{CSR}+\alpha \_2 \quad$ (C)

$\wedge * \mathrm{MANJ}+\alpha \quad 3 \quad$ [CSR \^* $\mathrm{INST}+\alpha 4$

MANJ $+\alpha 5^{-}$INST $+\alpha \_6 \quad \mathrm{SAL}+\alpha_{-} 7$

$\mathrm{LEV}+\mathrm{e}$

Dengan taraf kepercayaan 95\%, maka hipotesis yang diuji adalah sebagai berikut:

H03: GCG tidak dapat memoderasi CSR

terhadap kinerja perusahaan

Ha3: GCG memoderasi CSR terhadap kinerja perusahaan

Tabel 10

Hasil Pengujian $\mathrm{H3}$

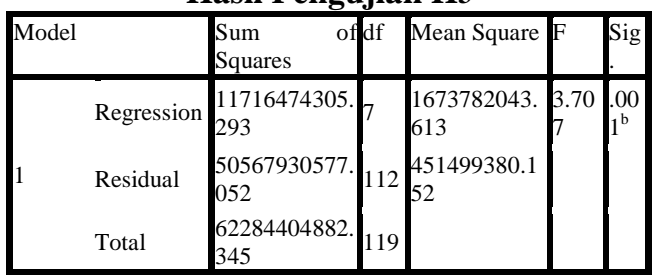

a. Dependent Variable: Kinerja Perusahaan

b. Predictors: Konstanta, Leverage, Sales Growth, CSR*Kepemilikan Manajerial, INST, CSR, CSR*Kepemilikan Institusional, MANJ

Untuk Hipotesis 3 dihasilkan nilai signifikansi hitung 0.001 , menunjukkan taraf signifikansi dibawah dari 0,05 . Jadi, tolak $\mathrm{H} 03$ dan terima $\mathrm{Ha}$, artinya GCG memoderasi CSR terhadap kinerja perusahaan.

Tabel 11

Analisis Uji Hipotesis Untuk H3 Model Summary ${ }^{\mathrm{b}}$

\begin{tabular}{|l|l|l|l|l|}
\hline Model & $\mathrm{R}$ & R Square & $\begin{array}{l}\text { Adjusted R } \\
\text { Square }\end{array}$ & $\begin{array}{l}\text { Std. Error of } \\
\text { the Estimate }\end{array}$ \\
\hline 1 & $.434^{\mathrm{a}}$ & .188 & .137 & 21248.51478 \\
\hline
\end{tabular}

a. Predictors: Konstanta, Leverage, Sales Growth, CSR*Kepemilikan Manajerial, INST, CSR, CSR*Kepemilikan Institusional, MANJ

b. Dependent Variable: Kinerja Perusahaan

Dalam tabel 11 dihasilkan R square sebesar 0.188. Maka:

Koefisien Determinan $=\mathrm{R}^{2} \times 100 \%$

Koefisien Determinan $=0.188 \times 100 \%$

Koefisien Determinan $=18.8 \%$

Dengan demikian, pengaruh GCG yang memoderasi CSR terhadap kinerja perusahaan adalah sebesar $18.8 \%$.

Ini berkaitan terhadap penelitian sebelumnya yang di lakukan oleh Retno Kusuma Dewi \& Bambang Widagdo (2012) dengan judul "Pengaruh Corporate Social Responsibility dan Good Corporate Governance Terhadap Kinerja Perusahaan" yang dimana variabel GCG memoderasi variabel CSR terhadap Kinerja Perusahaan.

\section{Hasil Pengujian Hipotesis}

Pengujian ini di buat untuk mengetahui nilai $\mathrm{p}$-value dengan signifikansi alfa $=$ $0,0.5$. 
Tabel 12

Hasil Pengujian Hipotesis

\begin{tabular}{|c|c|c|c|c|c|}
\hline \multicolumn{4}{|c}{ Path } & $\begin{array}{c}\text { Std. } \\
\text { Estimate }\end{array}$ & p-value \\
\hline H1 & CSR & $\rightarrow$ & KP & $\begin{array}{c}20908.9968 \\
6\end{array}$ & 0.000 \\
\hline H2 & GCG & $\rightarrow$ & KP & $\begin{array}{c}21070.4471 \\
3\end{array}$ & 0.000 \\
\hline & $\begin{array}{c}\text { GCG } \\
\text { mod } \\
\text { erasi } \\
\text { CSR }\end{array}$ & $\rightarrow$ & KP & $\begin{array}{c}21248.5147 \\
8\end{array}$ & 0.001 \\
\hline
\end{tabular}

\begin{tabular}{|c|c|c|}
\hline R Square & $\begin{array}{c}\text { Adjusted R } \\
\text { Square }\end{array}$ & Kesimpulan \\
\hline 0.431 & 0.431 & positif, signifikan \\
\hline 0.187 & 0.152 & positif, signifikan \\
\hline 0.188 & 0.137 & positif, signifikan \\
\hline
\end{tabular}

Tabel 13

Hasil Pengujian Variabel Kontrol

\begin{tabular}{|c|c|c|c|c|}
\hline \multicolumn{3}{|c|}{ Path } & Std. Estimate & p-value \\
\hline $\mathrm{SAL}$ & $\rightarrow$ & KP & 0.082 & 0.372 \\
\hline $\mathrm{LEV}$ & $\rightarrow$ & KP & -0.179 & 0.051 \\
\hline
\end{tabular}

\begin{tabular}{|c|c|c|}
\hline R Square & $\begin{array}{c}\text { Adjusted R } \\
\text { Square }\end{array}$ & Kesimpulan \\
\hline 0.007 & 0.002 & $\begin{array}{c}\text { positif, tidak } \\
\text { signifikan }\end{array}$ \\
\hline 0.031 & 0.024 & $\begin{array}{c}\text { positif, tidak } \\
\text { signifikan }\end{array}$ \\
\hline
\end{tabular}

\section{Simpulan dan Saran}

\section{Simpulan}

Di tahun 2015-2017 banyak perusahaan terdaftar di BEI sudah banyak menggunakan CSR. Hal ini berlandaskan dari penelitian yang mengambil sampel 40 dari 140 perusahaan di BEI pada tahun 2015-2017 sudah melakukan praktek CSR.

Perusahaan melakukan CSR, serta lingkungan kegiatan manajemen karena mereka mengharapkan untuk mendorong inovasi dan meningkatkan kinerja sosial perusahaan (Păunescu, 2014). CSR dan kinerja perusahaan yang mempunyai hubungan positif membuktikan bahwa biaya eksplisit perusahaan bukan biaya tersembunyi untuk pemangku kepentingan.Biaya yang dikeluarkan oleh perusahaan dalam praktik CSR akan jauh lebih rendah daripada manfaat corporate social responsibility (Porter dan Kramer, 2002). Jadi, jika perusahaan memperlakukan corporate social responsibility dengan serius, mereka meningkatkan biaya dengan daya saing dan mengurangi biaya yang tersembunyi bagi para pemangku kepentingan.

Perundang-undangan di Indonesia sudah mengatur CSR dijelaskan bahwa bagaimana cara perusahaan mengatur tanggung jawab sosial dan juga dengan lingkungan hidup. Penerapan CSR di Indonesia masih belum berjalan dengan tepat karena masih banyak perusahaan yang belum melaksanakan CSR.Maka perlu dibentuknya badan khusus atau dewan yang koordinatif dengan tujuan untuk mengawasi pelaksanaan CSR di Indonesia.

\section{Kerbatasan}

Keterbatasannya adalah: 1. Jumlah sampel yang dibatasi hanya 40 perusahaan manufaktur. 2.Jumlah populasi dibatasi hanya 144 perusahaan manufaktur.

\section{Saran}

Hendaknya: 1. Jumlah sampel agar jangan dibatasi hanya kelompok industri tertentu saja, 2.Sampel perusahaan yang digunakan lebih baik memakai sampel yang luas secara internasional. Jadi lebih banyak perusahaan yang di uji. 


\section{Daftar Pustaka}

Arifulsyah, H., \& Nurulita, S., (2016). "Analisis Pengaruh CSR Disclosure Terhadap Financial Performance Dengan Financial Leverage Dan Company Size Sebagai Variabel Moderating", Ekspansi, Vol. 8, No. 1 (Mei 2016), pp. 61 - 75.

Anggraini, R. R. 2006. "Pengungkapan Informasi Sosial dan Faktor Yang Mempengaruhi Pengungkapan Informasi Sosial dalam Laporan Keuangan Tahunan".Simposium Nasional Akuntansi IX. Padang, 23-26 Agustus.

Basuony, M.A.K., Elseidi, R.I., \& Mohamed, E.A.K. (2014). "The Impact Of Corporate Social Responsibility On Firm Performance: Evidence Form A Mena Country", Corporate Ownership \& Control, Volume 12, Issue 1, 2014, pp. 761-774.

Barnett, M. and Salomon, R. (2012), "Does it pay to be really good? Addressing the shape of the

relationship between social and financial performance", Strategic Management Journal, Vol. 33, No. 11, pp. 1304-1320.

Berete, M. (2011).Relationship between Corporate Social Responsibility and Financial Performance in the Pharmaceutical Industry, Unpublished Ph.D. dissertation, Walden University.

Barnea, Amir \& Amir Rubin. (2006). "Corporate Social Reponsibility as a Conflict between Shareholders". Paper presented to EFA 2006 Zurich Meeting, Swiss, Europe.

Castelo, M. and Lima, L. 2006. Corporate social responsibility and resourcebased perspectives, Journal of Business Ethics, 69: 32-11
Dewi, R. K., \& Widagdo, B. (2012)."Pengaruh Corporate Social Responsibility Dan Good Corporate Governance Terhadap Kinerja Perusahaan", Jurnal Manajemen Bisnis.Vol 2, No 1. Pp. 81-97.

Dabas, C.S. (2011). Doing well by doing good or doing smart? antecedents and outcomes of corporate social performance, Unpublished Ph.D. dissertation. Michigan State University.

Eksandy, A. (2018). "Pengaruh Good Corporate Governance Terhadap Kinerja Keuangan pada Perbankan Syari'ah Indonesia", Jurnal Akuntansi, Vol 5 No. 1, Januari 2018, pp. 1-10.http://dx.doi.org/ 10.30656/jak.v5i1.498

Fahmi, I. (2012). Pengantar Pasar Modal. Bandung: Alfabeta.

Friedman, Andrew L. (2006). Stakeholders: Theory and Practice. Oxford: Oxford University Press.

Gunawan, T. \& Sutiono, F. (2018). "Pengujian Good Corporate Governance dan Ukuran Perusahaan terhadap Kinerja Perusahaan", Jurnal Online Insan Akuntan, Vol.3, No.1, Juni 2018, pp. 21-30.

Hery. (2015). Analisis Laporan Keuangan. Yogyakarta: CAPS.

Harjoto, M., Laksmana, I. and Lee, R. (2015), "Board diversity and corporate social responsibility", Journal of Business Ethics, Vol. 132 No. 4, pp. 641-660.

Kholida, N., \& Susilo, D. E. (2019). Pengaruh Corporate Social Responsibility Terhadap Nilai Perusahaan Dengan Profitabilitas Sebagai Variabel Moderasi (Studi Empiris Pada Perusahaan Sektor Pertambangan Batubara Yang Terdaftar di Bursa Efek Indonesia Periode Tahun 2017-2018). Seminar Nasional Ekonomi \& Bisnis Dewanatara Call For Peper 2019 https://ejournal.stiedewantara.ac.id/i 
ndex.php/SNEB/issue/view/46 Hal. $79-88$.

Kamil, Ahmad dan Antonius Herusetya. 2012.

Pengaruhkarakteristik

Perusahaan terhadap Luas

Pengungkapan Kegiatan Corporate

Social Responsibility. Jurnal Media

Riset Akuntansi.Vol 2, No. 1.

Haniffa, R.M., dan T.E. Cooke (2005), "The Impact of Culture and Governance on Corporate Social Reporting", Journal of Accounting and Public Policy 24, pp. 391-430.

Jenkins, L. (2005). Mazimzing Range of Motion In Older Adult. The Journal on Active Aging. January February, 50-5.

Kabir, R. \& Thai, H.M. (2017) "Does corporate governance shape the relationship between corporate social responsibility and financial performance?",Pacific Accounting Review, Vol. 29 Issue: 2, pp.227258, https://doi.org/10.1108/PAR10-2016-0091.

Khanifar, H., Nazari, K., Emami, M., \& Soltani, H. A. (2012). Impacts Corporate Social Responsibility Activities On Company Financial Performance. Interdisciplinary Journal Of Contemporary Research in Business, 3(9), 583-592.

Liu, Y., Miletkov, M.K., Wei, Z. and Yang, T. (2015), "Board independence and firm performance in China”, Journal of Corporate Finance, Vol. 30, pp. 223-244.

La Porta, R., Silanes, F.L.D., Shleifer, A., and Vishny, R.W. (1997). "Legal Determinants of External Finance", The Journal Of Finance, Vol. LII, No. 3.

Maignan, I., \& Ferrell, O. C. (2004). Corporate Social Responsibility and Marketing: An Integrative Framework. Journal of the Academy of Marketing Science. Volume 32, No. 1, pages 3-19. DOI: 10.1177/0092070303258971.
Porter, E.M. \& Kramer, R.K. (2006). Strategy \& Society, The Link Between Competitive Advantage and Corporate Social Responsibility. Harvard Business Review, December 2006

Păunescu, C. (2014). "Current trends in social innovation research: social capital, corporate social responsibility,impact measurement", Management \& Marketing, Challenges for the Knowledge Society, Vol.9, No. 2, pp. 105-118.

Radjab, E. \& Jam'an, A. (2017).Metodologi penelitian bisnis. Makassar: Lembaga Perpustakaan dan Penerbitan Universitas Muhammadiyah Makassar.

Suhadak, Kurniaty, Handayani, S.R., and Rahayu, S.M. (2019). "Stock return and financial performance as moderation variable in influence of good corporate governance towards corporate value", Asian Journal of Accounting Research, Vol. 4 No. 1, 2019, pp. 18-34.https://doi.org/ 10.1108/AJAR-07-2018-0021.

Simionescu, L., \& Gherghina, S.. (2014). Corporate Social Responsibility And Corporate Performance: Empirical Evidence From A Panel Of The Bucharest Stock Exchange Listed Companies. Management \& Marketing Challenges for the Knowledge Society, Vol. 9, No. 4, pp. 439-458.

Sutantoputra, A.W. (2009). "Social disclosure rating system for assessing firms' CSR reports", Corporate Communications: An International Journal", Vol. 14 Iss 1 pp. $34-48$

http://dx.doi.org/10.1108/135632809 10931063

Sutantoputra, A. W. (2009). Social Disclosure Rating System For Assessing Firms Corporate Social Responsibility Reports. Corporate Communications: An International 
Journal, Volume 14, Number 1, 2009, pp. 34-48(15).

Sayekti, Y. dan L. S. Wondabio.(2007). "Pengaruh CSR Disclosure terhadap Earning Response Coefficient". Simposium Nasional Akuntansi X. Makassar, 26-28 Juli.

Stroup, M.A., Neubert, R.L., and Anderson, J. (1987). Doing good, doing better: Two views of social responsibility. Business Horizons, Vol. 30, issue 2, 22-25.

Veno, A. (2015). Pengaruh Good Corporate Governance Terhadap Kinerja Perusahaan pada Perusahaan Manufaktur Go Public. Jurnal Manajemen dan Bisnis. Vol 19, No 1 Halaman 95-112.

Wati, L. N., Syahdam, G. R., \& Prambudi, B. (2019).Peran Pengungkapan CSR Dan Mekanisme GCG Pada Kinerja Keuangan Terhadap Nilai Perusahaan. Jurnal Ecodemica, Vol. 3 Halaman 98-110.

Yuan, W., Bao, Y., \& Verbeke, A. (2011). "Integrating CSR Initiatives in Business: An Organizing Framework", Journal of Business Ethics, pp. 101:75 - 92 . DOI 10.1007/s10551-010-0710-z.

Yang, F. J., Lin, C. W., \& Chang, Y. N. (2010).The linkage between corporate social performance and corporate financial performance. African Journal of Business Management, 4(4), 406-413. 